\title{
In Situ Synthesis of Al-Based MMCs Reinforced with AlN by Mechanical Alloying under $\mathrm{NH}_{3}$ Gas
}

\author{
E. S. Caballero ${ }^{1, *(1)}$, F. G. Cuevas ${ }^{2}$, F. Ternero ${ }^{1}$ (D), R. Astacio ${ }^{1}$, J. M. Montes ${ }^{1}$ and J. Cintas ${ }^{1}$ (i) \\ 1 Escuela Técnica Superior de Ingeniería, Universidad de Sevilla, Camino de los Descubrimientos, \\ s/n. 41092 Sevilla, Spain; fternero@us.es (F.T.); rastacio@us.es (R.A.); jmontes@us.es (J.M.M.); \\ jcintas@us.es (J.C.) \\ 2 Escuela Técnica Superior de Ingeniería, Universidad de Huelva, Campus El Carmen, Avda. 3 de marzo, \\ s/n. 21071 Huelva, Spain; fgcuevas@dqcm.uhu.es \\ * Correspondence: esanchez3@us.es; Tel.: +34-954-487-313
}

Received: 23 April 2018; Accepted: 15 May 2018; Published: 17 May 2018

\begin{abstract}
Aluminum matrix composites (AMCs) reinforced by aluminum nitride were prepared by mechanical alloying followed by a simple press and sintering method. Milling began under vacuum and after a period of between 1 and $4 \mathrm{~h}, \mathrm{NH}_{3}$ gas flow $\left(1 \mathrm{~cm}^{3} / \mathrm{s}\right)$ was incorporated until the total milling time of $5 \mathrm{~h}$ was reached. Results show that in addition to the strain hardening taking place during mechanical alloying, $\mathrm{NH}_{3}$ plays an additional role in powder hardening. Thereby, the properties of the sintered compacts are strongly influenced by the amount of $\mathrm{N}$ incorporated into the powders during milling and the subsequent formation of AlN during the consolidation process. The obtained AMC reaches tensile strengths as high as $459 \mathrm{MPa}$ and hardness much higher than that of the as-received aluminum compact.
\end{abstract}

Keywords: aluminum; AMCs; powder metallurgy; mechanochemical processing; mechanical properties

\section{Introduction}

Because of their low weight and moderate strength, aluminum alloys are of great interest for a wide range of structural applications, especially in the aerospace and automotive industries $[1,2]$. However, the increasing demand for a high specific strength and properties stability at elevated temperatures $[3,4]$ make necessary the development of new aluminum alloys. The improvement of these properties can be achieved through new aluminum matrix composites (AMCs) [5-7], which are based in an aluminum matrix reinforced by ceramic particles. Because of their excellent properties, AMCs are nowadays widely used in sectors such as transportation, aerospace, electronics, sports, and infrastructure industries [8,9]. Traditionally, $\mathrm{SiC}$ and $\mathrm{Al}_{2} \mathrm{O}_{3}$ particles have been mainly used as reinforcement phases [10-14], but the desired performance improvements have led to reinforcing with many other types of ceramic particles $\left(\mathrm{Si}_{3} \mathrm{~N}_{4}, \mathrm{AlN}, \mathrm{B}_{4} \mathrm{C}, \mathrm{TiC}, \mathrm{ZrB}_{2}, \mathrm{TiB}_{2}\right)$. There are several methods by which to produce AMCs, including stirring casting [15], pressure infiltration $[7,10,16]$, spray deposition, accumulating roll bonding [17], centrifugal casting [18], and powder metallurgy [19].

MMC (metal matrix composite) properties can be controlled by using different types, amounts, sizes, and morphologies of the reinforcement, it being very important for these particles to be homogeneously distributed in the matrix. Over the last few years, studies have been conducted to achieve a good distribution of the reinforcing particles, as well as the optimal reinforcement-matrix volume ratio [13]. One of the manufacturing processes allowing the reaching of these aims is mechanical alloying (MA), with continuous fracture and welding processes taking place between the matrix and reinforcements incorporated into the mill, producing the desired microstructure. In addition, if chemical reactions are activated during milling (mechanosynthesis), the reinforcing 
phases can be obtained in situ or in a subsequent heating process, producing an even better homogeneous distribution of the reinforcements [20]. In these cases, the main challenge is to generate the appropriate reinforcement phases, and control both their size and percentage.

The aim of this work is to produce AMCs reinforced with a self-forming nitride dispersion. To this end, the aluminum-matrix powder was processed in a high-energy ball mill, and an ammonia gas flow was incorporated to produce a gas-solid reaction. The weight percentage of the nitrogen-rich phases was controlled by using different $\mathrm{NH}_{3}$ gas flow times. Thus, a combination of different sequences of vacuum and ammonia gas was carried out for a total milling time of five hours. After the milling process, powders were analyzed and compacts were made from them to study their mechanical properties.

\section{Materials and Experimental Procedure}

The starting material was atomized elemental aluminum powder (AS 61, Eckart) with a purity level higher than $99.7 \%$ and a mean particle size of $80.5 \mu \mathrm{m}$. The Al powder was processed in a high-energy attritor ball mill. The water-cooled stainless steel vessel had a capacity of $1400 \mathrm{~cm}^{3}$. A $3 \mathrm{wt} \%$ ethylene bis-stearamide organic wax (EBS, Licowax ${ }^{\circledR} \mathrm{C}$ micro powder PM Clariant, Basel, Switzerland) was used to balance the welding and fracture processes of the Al powders during milling. The mill contained $72 \mathrm{~g}$ of powder and $3600 \mathrm{~g}$ of high-chromium steel balls (charge ratio 50:1). All milling experiments were performed with a rotor speed of $500 \mathrm{rpm}$, at room temperature. In order to study the influence of the $\mathrm{NH}_{3}$ milling time on the formation of nitrogen-rich phase reinforcements, the ammonia flow period was extended from 1 to $4 \mathrm{~h}$. As a layer of $\mathrm{Al}_{2} \mathrm{O}_{3}$ covers the aluminum particles, all the experiments started under vacuum with the aim of eliminating and improving the reactivity of such particles with the $\mathrm{NH}_{3}$ gas. Thus, the experiments started under vacuum, and after a period of between 1 and $4 \mathrm{~h}$, ammonia $\left(\mathrm{NH}_{3}\right)$ gas flow $\left(1 \mathrm{~cm}^{3} / \mathrm{s}\right.$, purity $>99.96 \%$, Air Liquide) was incorporated until the total milling time of $5 \mathrm{~h}$ was reached [21]. Table 1 summarizes the milling time under vacuum and $\mathrm{NH}_{3}$ gas flow for the different milling experiments. Additionally, the effect of using a shorter ammonia flow, in particular for $10 \mathrm{~min}\left(10^{\prime} \mathrm{A}\right)$, was also studied. In this case, ammonia flow was incorporated after $2 \mathrm{~h}$ of milling, and then millings continued under vacuum until reaching $5 \mathrm{~h}$.

Table 1. Milling time conditions $(\mathrm{V}=$ Vacuum and $\mathrm{A}=$ Ammonia gas flow).

\begin{tabular}{cccc}
\hline Test Case & Vacuum Period (h) & $\mathbf{N H}_{3}$ Gas Flow Period (h) & Sample \\
\hline 1 & 5 & 0 & $5 \mathrm{~V}$ \\
2 & 4 & 1 & $4 \mathrm{~V}+1 \mathrm{~A}$ \\
3 & 3 & 2 & $3 \mathrm{~V}+2 \mathrm{~A}$ \\
4 & 2 & 3 & $2 \mathrm{~V}+3 \mathrm{~A}$ \\
5 & 1 & 4 & $1 \mathrm{~V}+4 \mathrm{~A}$ \\
\hline
\end{tabular}

All milled powders were consolidated by uniaxial cold pressing at $850 \mathrm{MPa}$ and vacuum sintering (5 Pa) at $650{ }^{\circ} \mathrm{C}$ for $1 \mathrm{~h}$, followed by furnace cooling. For comparison purposes, as-received aluminum powder (AR Al) was also consolidated by the same process. EBS wax was also used as the die-wall lubricant during cold pressing. Both cylindrical- (diameter: $12 \mathrm{~mm}$; mass: $4 \mathrm{~g}$ ) and tensile-shaped specimens [22] were produced.

A universal testing machine (Instron 5505, Instron, Norwood, MA, USA) with a load cell of $100 \mathrm{kN}$ was used to evaluate the compressibility of the powders. X-ray diffraction analysis (XRD, Bruker D8 Advance, using CuK $\alpha$ radiation, step size of $0.015^{\circ}$, and time step of $0.5 \mathrm{~s}$, Bruker, Billerica, MA, USA) was used to identify and quantify the phases formed. The compacts density (He Pycnometer, Accupyc II 1340, Micromeritics, Norcross, GA, USA), Brinell hardness (Emco M4U-025, Emco, Kellau, Kuchl, Austria), and tensile properties (Instron 5505) were also measured. Fractographic studies were performed using field emission scanning electron microscopy (FEGSEM, Fei Teneo, Lausanne, 
Switzerland) Because of the different densities of the $\mathrm{Al}$ matrix and the second phases appearing after a considerable amount of sintering, the absolute density of each sintered material needs to be computed. The resulting value will be considered to determine the relative density by comparing with the measured values.

\section{Results and Discussion}

\subsection{Powder Compaction Aptitude}

The compaction ability of the different produced powders was determined by a compressibility test, which measures the relative green density $(\mathrm{Dg})$ versus the applied compaction pressure. These curves are very useful for the consolidation process, allowing determination of the adequate compaction pressure to achieve the desired green density. Compressibility curves of the different milled powders are shown in Figure 1. As can be seen, results show that the relative density of the different powders decreases for a particular applied pressure as the ammonia milling period is prolonged. Thus, $\mathrm{Al}$ powder milled under vacuum $(\mathrm{V})$ for $5 \mathrm{~h}(5 \mathrm{~V})$ reaches relative densities above $90 \%$ for pressures of $500 \mathrm{MPa}$ or higher. Conversely, if aluminum powder is milled for $4 \mathrm{~h}$ under vacuum followed by $1 \mathrm{~h}$ under ammonia gas flow $(\mathrm{A} ; 4 \mathrm{~V}+1 \mathrm{~A})$, the relative density reaches values above $83 \%$ for the same pressure range. In this case, pressure must be increased up to $800 \mathrm{MPa}$ in order to reach the same level of densification as that achieved for $5 \mathrm{~V}$ powders. In the same way, for longer lasting ammonia gas flow millings $(3 \mathrm{~V}+2 \mathrm{~A}, 2 \mathrm{~V}+3 \mathrm{~A}$, and $1 \mathrm{~V}+4 \mathrm{~A})$, the relative density decreases, reaching values below $80 \%$ for a pressure of $500 \mathrm{MPa}$.

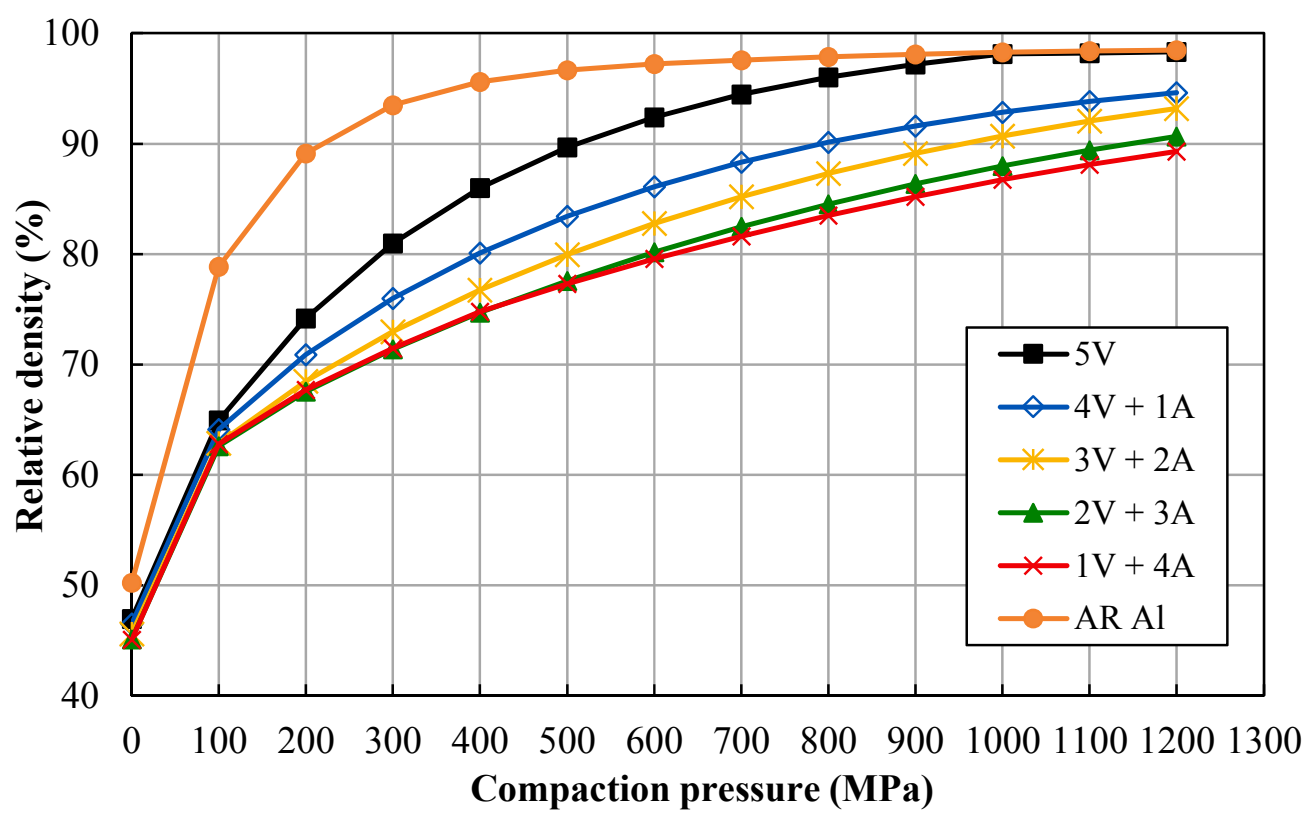

Figure 1. Compressibility curves of the different milled powders.

The compressibility test can also serve to estimate the hardness of the powder particles, showing the effect of the milling conditions. As shown in Figure 1, the relative density of the powders decreases by prolonging the ammonia gas flow, certainly because the powders become harder during the milling process. Thus, unmilled AR Al achieves relative densities higher than $90 \%$ from pressures of about $200 \mathrm{MPa}$, while vacuum-milled powder (5V) needs pressures greater than $500 \mathrm{MPa}$ to achieve similar densities. The soft $\mathrm{AR} \mathrm{Al}$, therefore, hardens after milling under vacuum $(5 \mathrm{~V})$ as a result of strain taking place during mechanical alloying. If $\mathrm{NH}_{3}$ is incorporated into the milling process, the achieved relative density decreases, and more so for longer intervals of $\mathrm{NH}_{3}$. Bearing in mind that the milling process lasted the same time for all the experiments and that the consolidation process was the same 
for all the powders, it is clear that the attained relative density directly depends on the milling time under ammonia gas flow.

The XRD patterns, corresponding to all the as-milled powders, show only $\mathrm{Al}$ peaks (Figure 2). However, after being heated, the reflections of aluminium nitride (AlN) and alumnium oxynitride $\left(\mathrm{Al}_{5} \mathrm{O}_{6} \mathrm{~N}\right)$ are observed besides those of the aluminium when ammonia is incorporated into the milling. This fact allows the statement that the dissociation of the ammonia gas occurs during milling, and nitrogen is kept as a solid in solution until the heat treatment activates the formation of the nitrogen-rich second phases.

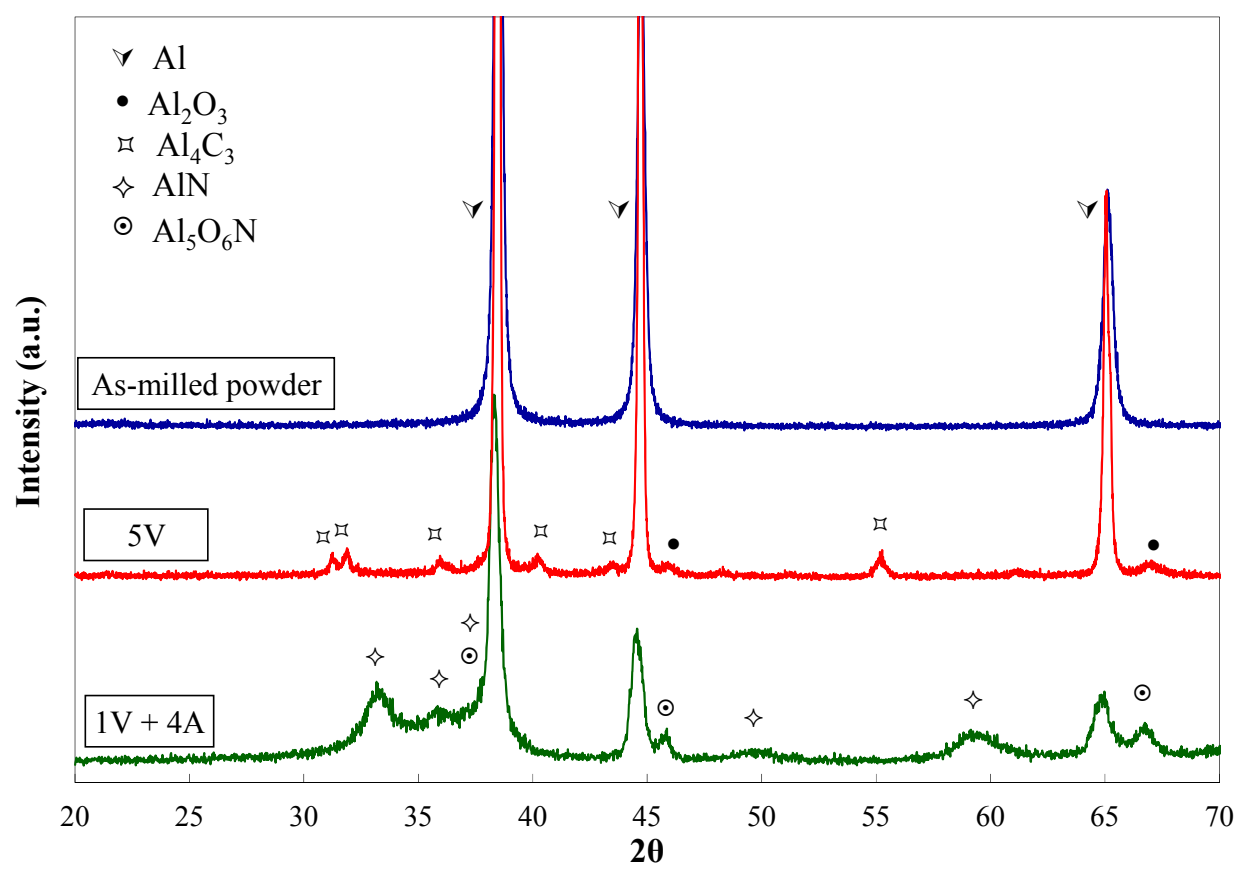

Figure 2. XRD patterns of as-milled powders and $5 \mathrm{~V}$ and $1 \mathrm{~V}+4 \mathrm{~A}$ powders after being milled and heat treated.

\subsection{Sintered Compact Properties}

After mechanical alloying, powders were consolidated to assess the influence of the ammonia flow time on the relative density, hardness, and tensile properties.

Figure 3 shows the relative density (D) and Brinell hardness (HB) of the different compacts after being pressed (green compacts) and sintered. It can be observed that the relative density of the $5 \mathrm{~V}$ compacts, both before and after sintering, is slightly lower than that of the AR Al. Furthermore, relative density decreases as ammonia flow time is prolonged. The longer the ammonia flow time, the higher the hardness of the powder and as a consequence, the lower the compressibility and the achieved relative density. As expected, the relative density slightly increases for any of the studied conditions after the sintering process.

Despite the fact that the relative density follows a decreasing trend with the increase of the ammonia flow time, it should be noted that hardness follows a growing tendency. After pressing, a remarkable increase of the Brinell hardness $\left(\mathrm{HB}_{\mathrm{g}}\right)$ is observed for those compacts made from milled powders with respect to the $\mathrm{AR} \mathrm{Al}$ compact. This increase is mainly due to strain hardening taking place during the milling process [23] as well as the resulting solid solution from the incorporation of nitrogen to the aluminum lattice [24]. After sintering, the same hardness was observed for compacts made from $\mathrm{AR} \mathrm{Al}$ and $5 \mathrm{~V}$ powders, while compacts made from powders milled under ammonia gas show a marked increase. The reaction taking place during the sintering process between $\mathrm{Al}$ and $\mathrm{N}$ gives rise to the formation of $\mathrm{Al}_{5} \mathrm{O}_{6} \mathrm{~N}$ and mainly, $\mathrm{AlN}[24,25]$. This new phase is ceramic in nature 
and therefore harder than $\mathrm{Al}$, therefore increasing the sintered compacts' hardness $(4 \mathrm{~V}+1 \mathrm{~A}, 3 \mathrm{~V}+2 \mathrm{~A}$, $2 \mathrm{~V}+3 \mathrm{~A}$ and $1 \mathrm{~V}+4 \mathrm{~A}$ ), in spite of the lower relative density achieved.

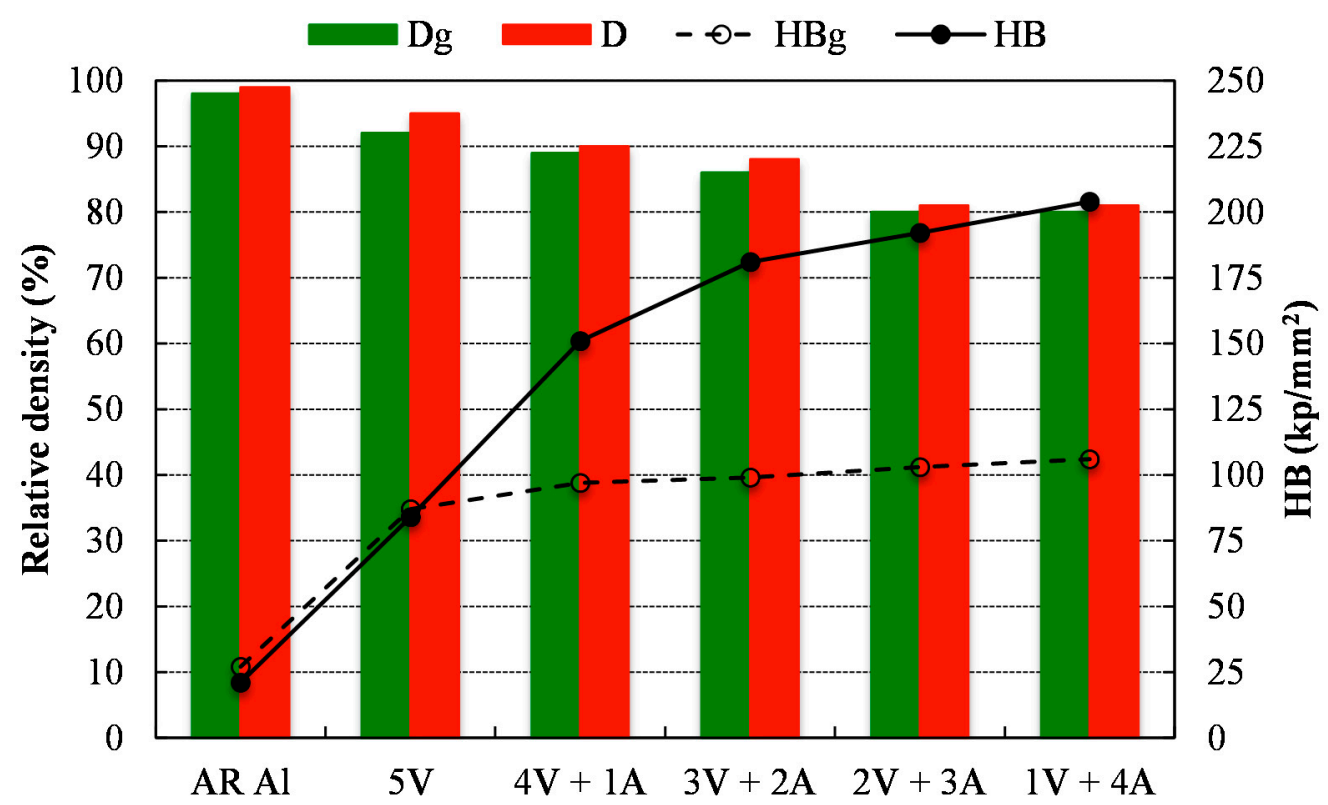

Figure 3. Relative density and hardness, both after pressing ( $\mathrm{D}_{\mathrm{g}}$ and $\mathrm{HB}$, respectively) and sintering (D and HB, respectively), of the different milled powders.

Figure 4 summarizes the evolution of both the weight percentage of AlN and the compact hardness. It can be observed that the amount of aluminum nitride increases with the milling time under ammonia, but the slope of the curve continuously decreases, and also does the percentage of AlN produced per hour. The direct effect on hardness of the AIN ceramic phase accounts for the similar trend observed in the hardness curve.

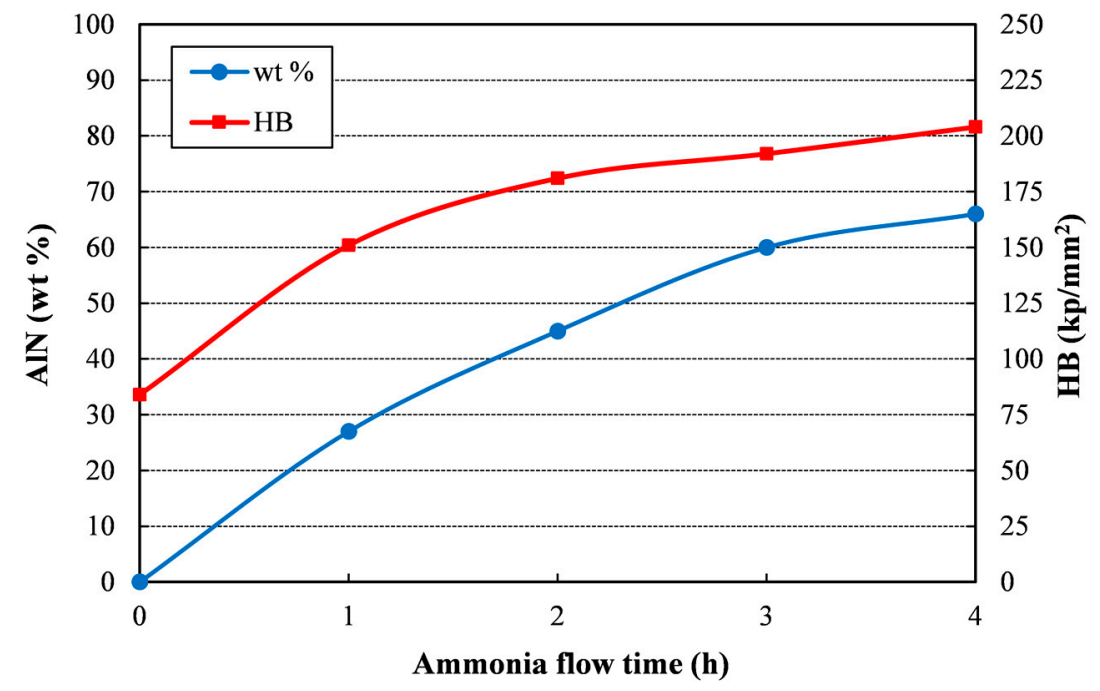

Figure 4. AlN wt \% and hardness versus ammonia flow time of the different sintered compacts.

Figure 5 shows the relative density and ultimate tensile strength (UTS) as a function of the AlN wt $\%$. As can be observed, both properties follow the same trend, with the UTS decreasing despite the strengthening observed in hardness tests by increasing the ammonia presence (Figures 2 and 3 ). The UTS of PM (Powder Metallurgy) parts is a function of both the relative density and the hardness of 
the individual powder particles, as long as good particle bonding has been achieved and the tensile test behaves in a ductile mode. On one hand, the relative density achieved after sintering decreases with the milling time under ammonia flow. Thus, the UTS tends to decrease due to the increase of porosity. Harder powders are obtained for longer millings under ammonia as a result of the solubilized $\mathrm{N}$, and lower densities can be attained after pressing. On the other hand, the direct effect of the hardness of individual particles can be observed by comparing the curves in Figure 5. The UTS decreases as a consequence of the decrease in relative density, but mainly because of the increase in fragile AlN particles formed from the solubilized N. For the first hour under ammonia flow $(4 \mathrm{~V}+1 \mathrm{~A})$, both curves are almost parallel. However, after the second hour under ammonia flow $(3 \mathrm{~V}+2 \mathrm{~A})$, the UTS remarkably decreases due to the AlN increase from $27 \%$ to $45 \%$. Finally, it can be observed that from the third to the fourth hour under ammonia gas $(2 \mathrm{~V}+3 \mathrm{~A}$ and $1 \mathrm{~V}+4 \mathrm{~A}$, respectively), the relative density no longer changes, but the UTS continues decreasing as a result of the increase in AlN from 60 to $66 \mathrm{wt} \%$. Clearly, the presence of such a large amount of fragile ceramic particles controls the material's behavior, and despite the aforementioned increase in hardness for longer millings under ammonia, the tensile response does not correspond to the expected performance in a harder ductile material.

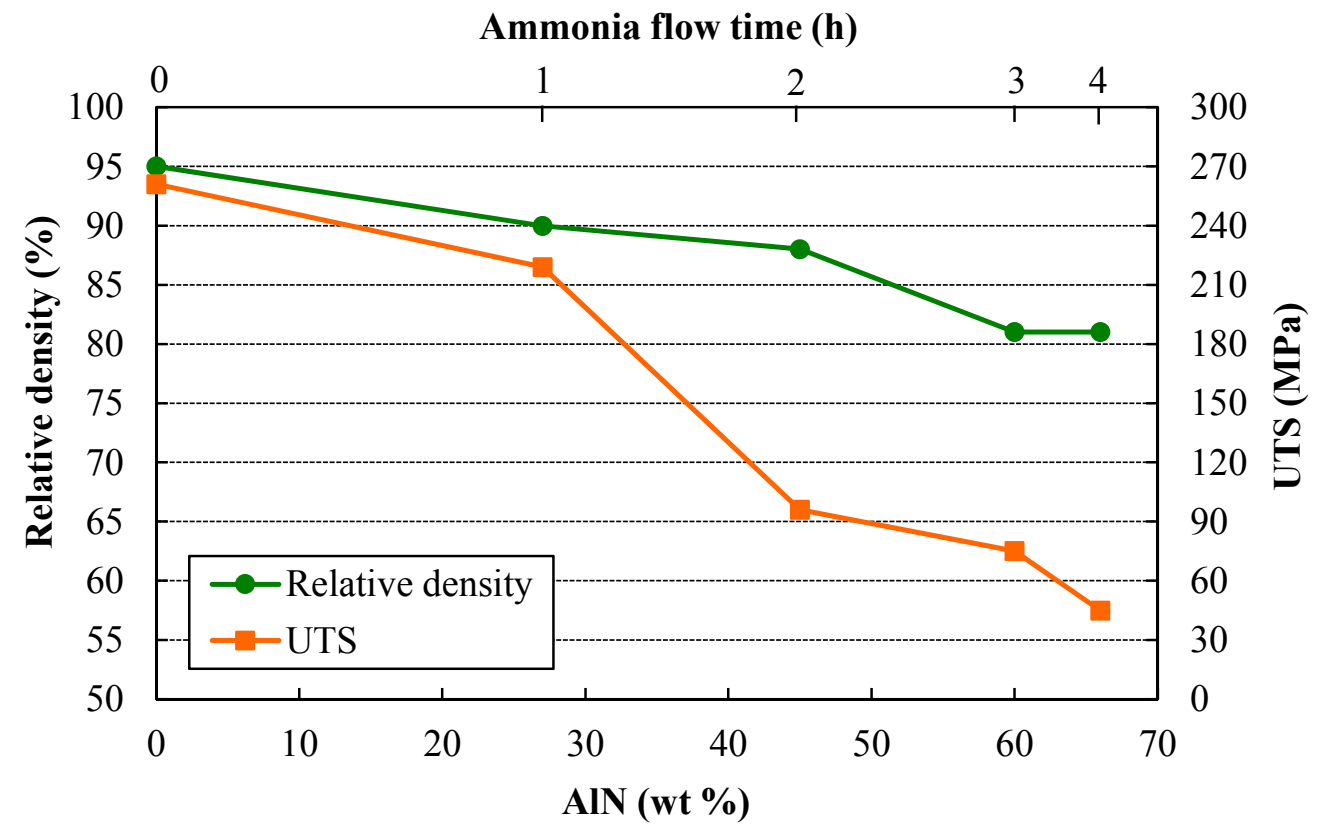

Figure 5. Relative density and UTS (Ultimate Tensile Strength) versus AlN wt \% of the different sintered compacts.

In order to reduce the high percentage of second phases, a different milling process was carried out. After two hours of milling under vacuum, a short ammonia gas flow was incorporated for ten minutes, continuing under vacuum until a total time of $5 \mathrm{~h}$ was reached $\left(10^{\prime} \mathrm{A}\right)$. In this way, the presence of AlN was reduced to $19 \mathrm{wt} \%$, and a relative density close to $100 \%$ was reached after the same pressing and sintering process. The resulting mechanical properties show a hardness of $167 \mathrm{kp} / \mathrm{mm}^{2}$ and a notable improvement in UTS (459 MPa). The achieved improvement is due to the high level of densification reached and the influence of an appropriate amount of ceramic particles. Figure 6 shows the fracture surface of the $10^{\prime} \mathrm{A}$ compact, as well as that of the $4 \mathrm{~V}+1 \mathrm{~A}$ and $1 \mathrm{~V}+4 \mathrm{~A}$ compacts. A low-porosity surface with rounded edges can be observed in the $10^{\prime} \mathrm{A}$ compact (Figure 6a), whereas the $4 \mathrm{~V}+1 \mathrm{~A}$ compact (Figure 6b) shows a higher porosity and sharper edges. Finally, in Figure 6c is observed an even lower density surface with a plentiful presence of loose particles, although the tensile strength achieves a considerable value. 

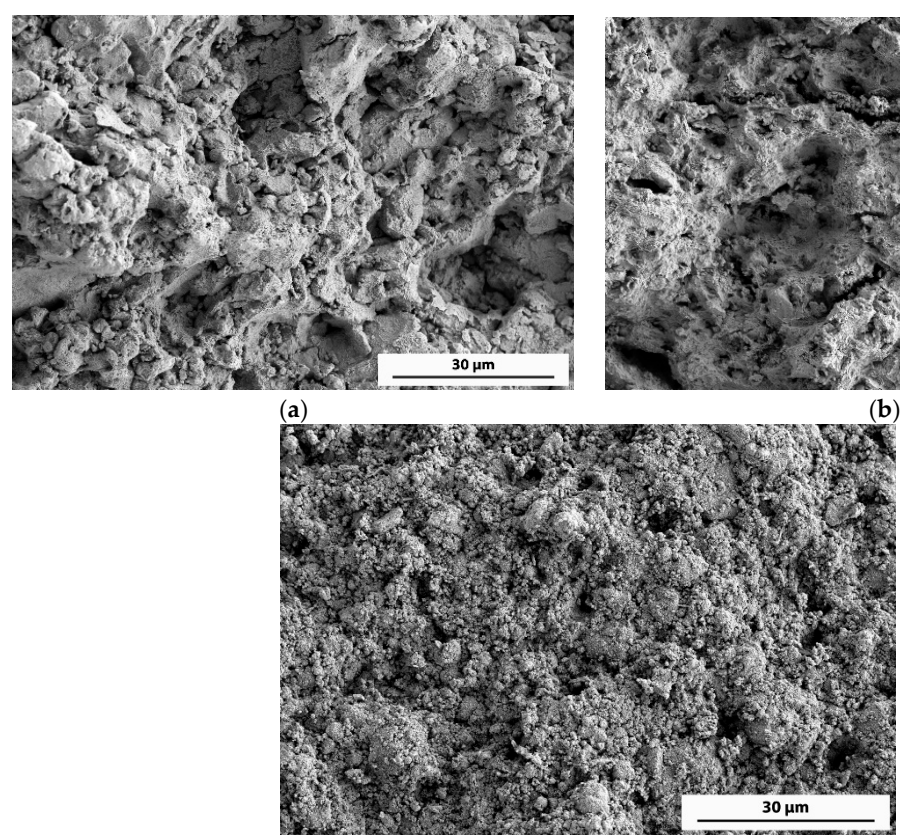

(c)

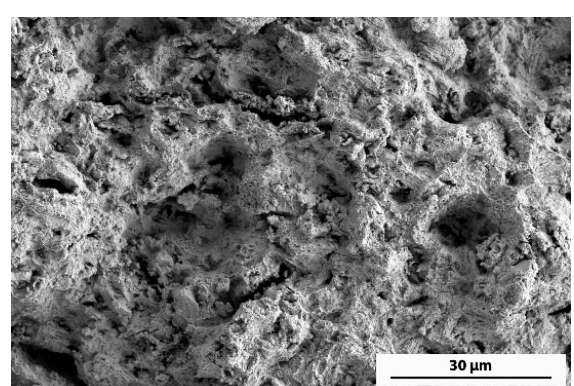

(b)

Figure 6. FEGSEM (field emission scanning electron microscopy) secondary electrons microfractographs of the fracture surface of (a) $10^{\prime} \mathrm{A},(\mathbf{b}) 4 \mathrm{~V}+1 \mathrm{~A}$, and (c) $1 \mathrm{~V}+4 \mathrm{~A}$ compacts.

Due to the high percentage of the refractory phase formed, the high-temperature behavior of the sintered compacts is expected to be noticeable. Thus, samples were heated for $100 \mathrm{~h}$ at $400{ }^{\circ} \mathrm{C}$ and hardness was then measured at this temperature, as well as at 300,200 , and $100{ }^{\circ} \mathrm{C}$ (Figure 7). As expected, hardness decreases as temperature increases for all samples. However, it can be observed that the hardness curves drastically decrease for long-lasting ammonia milling compacts, while it decreases more slowly for the $10^{\prime} \mathrm{A}$ compact as temperature rises. Furthermore, it is remarkable that the 10'A compact reaches the highest hardness values, in spite of its lower percentage of second phases. This is because the $10^{\prime} \mathrm{A}$ compact achieves a high-enough reinforcement of the aluminum matrix and at the same time, minimizes the porosity.

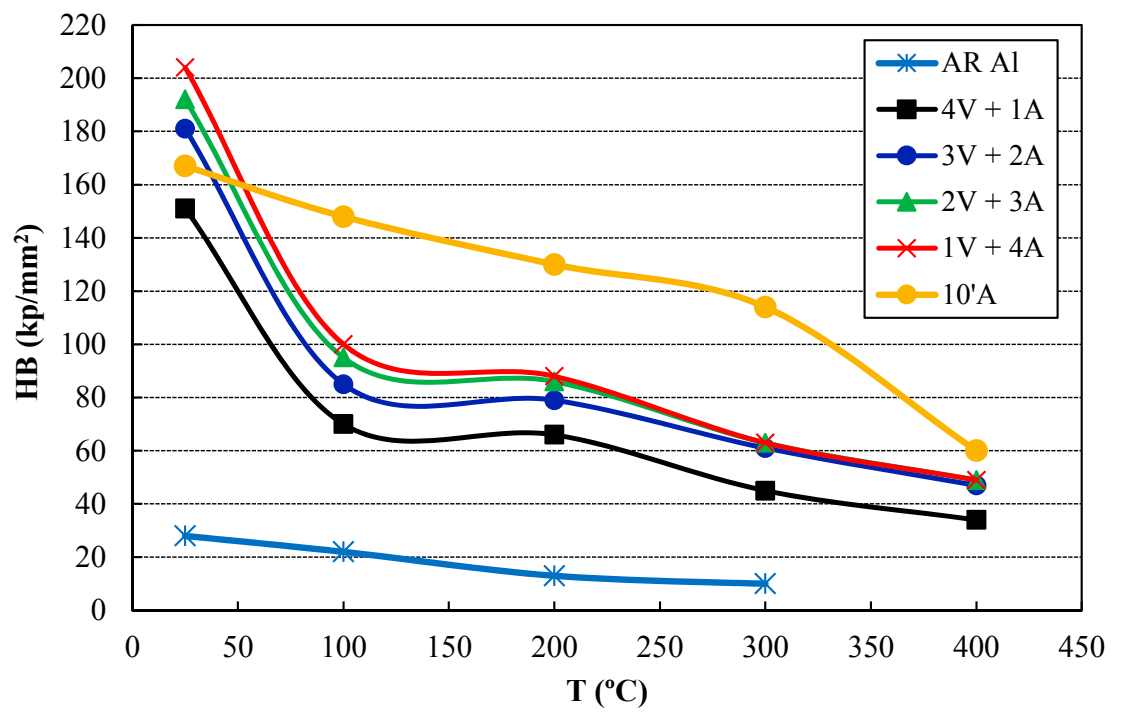

Figure 7. Hardness results of the sintered compacts measured at room temperature and at high temperatures after a heat treatment of $100 \mathrm{~h}$ at $400{ }^{\circ} \mathrm{C}$. 


\section{Conclusions}

The as-received aluminum powder was attrition milled under different cycles of vacuum (5 Pa) and ammonia gas flow $\left(1 \mathrm{~cm}^{3} / \mathrm{s}\right)$. Results show that in addition to strain hardening, which takes place during mechanical alloying, $\mathrm{NH}_{3}$ plays an additional role in powder hardening. In this way, at a consolidation pressure of $850 \mathrm{MPa}$, the relative green density is progressively reduced from about $97 \%$ to $84 \%$ (for $5 \mathrm{~V}$ and $1 \mathrm{~V}+4 \mathrm{~A}$ powders, respectively) when ammonia flow is prolonged, due to the increase of solubilized nitrogen. In this way, after sintering, hardness increases due to the AlN formed, while the UTS decreases as a consequence of the increase in porosity and the massive presence of fragile particles. Regarding the latter, fractographic study has revealed that a higher level of consolidation is achieved if the percentage of nitrogen-rich second phases is reduced. On the other hand, hardness tests carried out at high temperatures show that higher values are attained as the weight percentage of AlN increases. However, using an ammonia flow of $10 \mathrm{~min}$, the percentage of second phases was reduced to $19 \%$ and the porosity was minimized. As a result, a value of the UTS as high as $459 \mathrm{MPa}$ was reached, and the hardness at high temperatures resulted as being higher and more stable.

Author Contributions: E.S.C. and F.G.C. conceived and designed the experiments; F.T. and R.A. performed the experiments; J.M.M. analyzed the data; E.S.C., F.G.C. and J.C. wrote the paper.

Funding: Financial support of the Ministerio de Economía y Competitividad (MINECO/FEDER, Spain) through the research project DPI2015-69550-C2-1-P is gratefully acknowledged.

Acknowledgments: The authors are grateful to the Microscopy and XRD Central Services (CITIUS, University of Seville).

Conflicts of Interest: The authors declare no conflict of interest.

\section{References}

1. Sivananth, V.; Vijayarangan, S.; Rajamanickam, N. Evaluation of fatigue and impact behavior of titanium carbide reinforced metal matrix composites. Mater. Sci. Eng. A 2014, 597, 304-313. [CrossRef]

2. Machado, J.J.M.; Gamarra, P.M.-R.; Marques, E.A.S.; da Silva, L.F.M. Improvement in impact strength of composite joints for the automotive industry. Compos. Part B Eng. 2018, 138, 243-255. [CrossRef]

3. Mondol, S.; Alam, T.; Banerjee, R.; Kumar, S.; Chattopadhyay, K. Development of a high temperature high strength $\mathrm{Al}$ alloy by addition of small amounts of Sc and Mg to 2219 alloy. Mater. Sci. Eng. A 2017. [CrossRef]

4. Goebel, J.; Ghidini, T.; Graham, A.J. Stress-corrosion cracking characterisation of the advanced aerospace Al-Li 2099-T86 alloy. Mater. Sci. Eng. A 2016. [CrossRef]

5. Mohapatra, S.K.; Maity, K. Synthesis and characterisation of hot extruded aluminium-based MMC developed by powder metallurgy route. Int. J. Mech. Mater. Eng. 2017. [CrossRef]

6. Gladston, J.A.K.; Dinaharan, I.; Sheriff, N.M.; Selvam, J.D.R. Dry sliding wear behavior of AA6061 aluminum alloy composites reinforced rice husk ash particulates produced using compocasting. J. Asian Ceram. Soc. 2017. [CrossRef]

7. Narciso, J.; Molina, J.M.; Rodríguez, A.; Rodríguez-Reinoso, F.; Louis, E. Effects of infiltration pressure on mechanical properties of Al-12Si/graphite composites for piston engines. Compos. Part B 2016, 91, 441-447. [CrossRef]

8. Sharma, P.; Sharma, S.; Khanduja, D. Production and some properties of Si3N4 reinforced aluminium alloy composites. J. Asian Ceram. Soc. 2015, 3, 352-359. [CrossRef]

9. Lee, J.I.; Park, E.S. In-Situ synthesis of co-continuous aluminum-aluminum nitride composites by arc plasma induced accelerated displacement reaction. J. Alloys Compd. 2017, 729, 171-179. [CrossRef]

10. Miserez, A.; Stücklin, S.; Rossoll, A.; San Marchi, C.; Mortensen, A. Influence of heat treatment and particle shape on mechanical properties of infiltrated $\mathrm{Al} 2 \mathrm{O} 3$ particle reinforced $\mathrm{Al}-2 \mathrm{wt}-\% \mathrm{Cu}$. Mater. Sci. Technol. 2002, 18, 1461-1470. [CrossRef]

11. Knowles, A.J.; Jiang, X.; Galano, M.; Audebert, F. Microstructure and mechanical properties of $6061 \mathrm{Al}$ alloy based composites with SiC nanoparticles. J. Alloys Compd. 2014, 615, S401-S405. [CrossRef]

12. Canakci, A.; Varol, T. Microstructure and properties of AA7075/Al-SiC composites fabricated using powder metallurgy and hot pressing. Powder Technol. 2014. [CrossRef] 
13. Lakshmipathy, J.; Kulendran, B. Reciprocating wear behavior of $7075 \mathrm{Al} / \mathrm{SiC}$ in comparison with $6061 \mathrm{Al} / \mathrm{Al}$ $2 \mathrm{O} 3$ composites. Int. J. Refract. Met. Hard Mater. 2014, 46, 137-144. [CrossRef]

14. Ekinci, V.S.; Bagci, C.; Arik, H. Effect of Al2O3 content and milling time on microstructure and mechanical properties of aluminum metal matrix composites. Exp. Tech. 2014, 38, 66-73. [CrossRef]

15. Yigezu, B.S.; Jha, P.K.; Mahapatra, M.M. The key attributes of synthesizing ceramic particulate reinforced Al-based matrix composites through stir casting process: A review. Mater. Manuf. Process. 2013, 28, 969-979. [CrossRef]

16. Garcia-Cordovilla, C.; Louis, E.; Narciso, J. Pressure infiltration of packed ceramic particulates by liquid metals. Acta Mater. 1999, 47, 4461-4479. [CrossRef]

17. Alizadeh, M.; Paydar, M.H. Fabrication of nanostructure Al/SiCP composite by accumulative roll-bonding (ARB) process. J. Alloys Compd. 2010, 492, 231-235. [CrossRef]

18. Arsha, A.G.; Jayakumar, E.; Rajan, T.P.D.; Antony, V.; Pai, B.C. Design and fabrication of functionally graded in-situ aluminium composites for automotive pistons. Mater. Des. 2015, 88, 1201-1209. [CrossRef]

19. Torralba, J.M.; Da Costa, C.E.; Velasco, F. P/M aluminum matrix composites: An overview. J. Mater. Process. Technol. 2003, 133, 203-206. [CrossRef]

20. Cintas, J.; Montes, J.M.; Cuevas, F.G.; Herrera, E.J. Influence of milling media on the microstructure and mechanical properties of mechanically milled and sintered aluminium. J. Mater. Sci. 2005, 40, 3911-3915. [CrossRef]

21. Caballero, E.S.; Cintas, J.; Cuevas, F.G.; Montes, J.M.; Ternero, F.; Reina, F.J.V. Synthesis and characterization of in situ-reinforced Al-AIN composites produced by mechanical alloying. J. Alloys Compd. 2017, 728, 640-644. [CrossRef]

22. MPIF. Preparing and Evaluating Tensile Specimens of Powder Metallurgy Materials; MPIF Standard 10; MPIF: Princeton, NJ, USA, 2010.

23. Cintas, J.; Caballero, E.S.; Montes, J.M.; Cuevas, F.G.; Arevalo, C. Nanocrystalline Al Composites from Powder Milled under Ammonia Gas Flow. Adv. Mater. Sci. Eng. 2014, 2014, 1-8. [CrossRef]

24. Caballero, E.S.; Cintas, J.; Cuevas, F.G.; Montes, J.M.; Gallardo, J.M. A new method for synthetizing nanocrystalline aluminium nitride via a solid-gas direct reaction. Powder Technol. 2016, 287, 341-345. [CrossRef]

25. Caballero, E.S.; Cintas, J.; Herrera-García, M.; Cuevas, F.G.; Montes, J.M. Order Effect of Vacuum and Ammonia Atmospheres on Aluminium Nitriding by Mechanical Alloying. Mater. Sci. Forum 2012, 730-732, 936-941. [CrossRef] 